\title{
FEATURES OF UNDERSTANDING THE HUMAN MENTAL DEVELOPMENT IN THE VIEWS OF THE REPRESENTATIVES OF THE SCHOOL OF PHILOSOPHY OF PSYCHOLOGY OF THE LATE XIX - EARLY XX CENTURY
}

\section{Oksana Melnyk}

\section{INTRODUCTION}

Approaching the analysis of the world around us, we inevitably meet with complexes of phenomena that become understandable only when they are regarded as the result of development. For a long time there was a debate in psychological theory that what exactly in every studied fact need to be designated as development.

The development issue was developed in psychology too specifically, in terms of gaining experience, and the latter at the turn of the XIX - XX centuries tried to interpret not broadly biologically, but mechanically. Philosophy of psychology of the late XIX-beg. of the XX century, unlike other types, approached the issue of mental development, trying to reveal the peculiarities of this development, open general laws of mental development.

At the same time, according to representatives of philosophy of psychology, in no case should we forget that the object of psychological research is usually an adult, a creature that stands on the development ladder of a rather late stage. At the same time, a human is considered from three points of view: 1) compared to animals, 2) as a representative of a quite differentiated culture, 3 ) an adult compared to a child.

Often in the scientific sphere we can observe fundamentally contrary viewpoints of scientists on a certain issue during a certain historical period. The development of ideas about the nature of human psyche is not an exception. In the late 19th century, were formed two opposite psychologies, one of which was accused of failing to 
recognize the actual uniqueness of the human psyche, brings a human to the level of animal existence; the second direction was accused of losing in its emphasis the unique principles and requirements of science. In such accents, according to V.A. Romenets, there was historically limited truth ${ }^{1}$.

In the 19th century, a conceptual, philosophical approach to solving the issue of methodological foundationin of the formation of the subject of psychology begins to develop actively. It is the philosophical direction that becomes leading in the creation of psychological knowledge by teachers of the psychology course, scientists at the Kiev University of St. Volodymyr since its opening in 1834.

The specificity and uniqueness of psychological science is determined by representatives of the Kyiv School of Philosophy of psychology in its object, subject and objectives and possibilities of using the acquired knowledge, which it produces. There is a rather serious emphasis on the importance of psychological knowledge for the clerisy, public figures and those who have the desire and intention to influence public affairs and people 's lives, to create knowledge in general. At the end of the XIX - beg. of the XX century psychology of representatives of the Kyiv School of Philosophy of psychology is recognized as a science that studies psychical or mental phenomena and laws of psychical or mental life ${ }^{2}$. Thoughts, feelings, high ground decisions, mental states, conscious states - to see, feel, experience, come to any decision belong to the mental phenomena. At the end of the XIX - beg. of the XX century psychology of representatives of the Kyiv School of Philosophy of psychology is recognized as a science that studies psychical or mental phenomena and laws of psychical or mental life. Thoughts, feelings, high ground decisions, mental states, conscious states - to see, feel, experience, come to any decision belong to the mental phenomena. G.I. Chelpanov is convinced that the

1. P. RomenetsV.A. (2005). Istoriy psihologii. [History of psychology]. T. I. Kiev: Libid. (in Ukrainian). P.47.

${ }^{2}$ Zenkovskiy V.V., Sikorskiy I.A., Chelpanov G.I. 
description of mental phenomena and their integration, in case of similarity, allows to combine these phenomena into one common class. Mental phenomena are recognized as quite complex phenomena and in order to determine their nature it is necessary to carry out mental operation of decomposition into constituent parts or to cause analysis of them For example, "contemplation of any tragedy causes a complex mental state. To reveal exactly what thoughts and feelings accompany this state means the analysis of this state itself", And because of psyche, as G. Chelpanov convinced, it becomes possible to develop any mental states of a person ${ }^{4}$.

At the end of the XIX century, representatives of the Kyiv School of Philosophy of psychology began to use actively the word "psyche" instead of the word "soul." It can be explained quite simply. The soul is an invisible thing that cannot be directly observed and measured. And psychology, according to scientists, is a clear, serious and accurate science. Therefore, it was decided to study something that could both be observed and measured. And that is why during this period in the domestic psychological science there is a replacement in the designation relative to the subject of psychological science. The concept of "soul" and the concept of "psyche" were recognized as identical de facto, but were not resulted or separated from each other.

One of the key ideas about the human psyche of the representatives of the Kyiv School of Philosophy of psychology of the late XIX - beg. of the XX century turns out to be an idea for its development. Scientists emphasize that all phenomena of the surrounding world are in continuous movement, alternating opposite states, and stopping movement means stopping being. Scientists consider in general the whole dynamics of mental life of a person from these positions.

${ }^{3}$ RomenetsV.A. (2005). Istoriy psihologii. [History of psychology]. T. I. Kiev: Libid. (in Ukrainian). P. 6

${ }^{4}$ Chelpanov G.I. (1915). Chelpanov G.I. (1915). Ychebnik po psihologii (dly gimnaziy I ychilich)[Textbook of Psychology (for gymnasiums and self-education)]. Moscow: V.V. Dumnov. ( in Russian). 


\section{Understanding of the origin of psyche and the mental development of philosophy of psychology of the late XIX -early XX century}

With the emergence and adoption of the evolutionary hypothesis by the scientific community, animal psyche becomes one of the mandatory sections in the study of psychological science. It was believed that the study of animal psyche, simpler in its structure may contribute to the study of human psyche more complex in its structure.

In the domestic philosopho-psychological idea of the late XIX early XX century was believed that where there is no psyche and mental phenomena, the simplest event in life is the usual chemical and physical properties of protoplasm, and above them is something more complex - geotropism and heliotropism, which are characteristic for plants and animals. Geotropism is defined as the ability of plant organs to grow in a certain direction towards to the center of the earth, and heliotropism means the ability of plants to take a certain position under the influence of the sun. The phenomenon is based not on any involvement of the nervous system, but on simpler physiological phenomena. "For example, an grow of snowball," writes the representative of the Kyiv School of Philosophy of psychology, "according to the down movement or like spreading the process of contraction in muscle fiber if this process has begun anywhere in the fiber",5.

With the appearance of nervous tissue in the body of the animal occur the reflecting acts. I. Sikorskyi understands reflex as "machinelike act, always ready for action and similar to, for example, an electric call that rings continuously as soon as the current is made by pressing a button" . The professor also calls the reflex "the favorite apparatus of wildlife: reflex devices are scattered in the living body by thousands and are easily, quickly and accurately driven by irritation,

${ }^{5}$ Sikorskiy I.A. (1909). Nachatki psihologii. [The beginnings of psychology]. Kiev: S.V. Kulzhenko. (in Ukrainian). P. 18

${ }^{6}$ Sikorskiy I.A. (1909). Nachatki psihologii. [The beginnings of psychology]. Kiev: S.V. Kulzhenko. (in Ukrainian). P.18 
as, for example, eyelid flashes or closes by reflex as soon as a small object touches the eye or eyelashes", In general, many well-known acts are reflexes, such as swallowing, sneezing, and the like. Less common but such that play an important role are automatic acts, that is movements caused by direct irritation of the nervous cell, for example, lack of solid, liquid or gaseous food in the cell (hunger, thirst, apnoea, etc.). Instinct composed of a series of automatic and reflex irritations is recognized more complex and more diverse than reflex. But mental act is recognized as the highest. If between sensitive and motile nerve cells there is a cell in which impressions (memory cell) are stored and reflecting excitation will pass through the sensitive cell and memory cell, and then the final effect of movement will depend not only on irritation at the moment (perception), but also on those memories that will be caused. And it is the simplest combination of impressions that take place in the present with impressions that were in the past, which is the essence of mental act: it provides opportunities to join impressions of the past time to this perception - and thus expands the life experience itself. So, orienting responses, reflexes, instincts, perceptions, and memories inosculating together constitute a complex organ of mental life in which physical, physiological, and mental are united for the purposes of life.

In order to trace the main stages of mental evolution I. Sikorskyi proposes to focus only on those animals, which already have a considerable degree of expression of various versions of the psychic model.

People belong to the worm, the professor notes, as a creature that stands at a rather low stage of mental development. Worms cannot protect their lives, do not understand the danger and do not escape it. The reason for this phenomenon the representative of the Kyiv School of Philosophy of psychology considers that worms have no other senses than tactile perception. "The worm," the professor writes, "feels the outside world to the touch and starts the living motion only when

${ }^{7}$ Sikorskiy I.A. (1909). Nachatki psihologii. [The beginnings of psychology]. Kiev: S.V. Kulzhenko. (in Ukrainian). P. 18-19 
anything directly touches its skin. Having neither an eye nor an ear, the worm is absolutely deprived of the means to feel the outside world from a distance and to understand the proximity of danger" ${ }^{\prime 8}$. It follows that the worm can be easily caught, whereas the ant and butterfly escape and are eluded the grasp. But on the other hand ants have five senses, but use only sense of smell. Ants have all those external effects that are perceived by higher animals as well. With its untiring activity, the ant attracts special human attention. The unusual instincts that the ant has developed towards the arrangement of dwellings and the organization of public life deserve attention, I. Sikorskiy believes. Between insects, the ant has the largest brain in relation to the size of its body. "The ant is deservedly," writes the professor, "given the name "mental atom", as it is first who has the soul with all its main properties, that are, five senses, complex instincts, one feeling (anger) and extremely mobile activity, which is based on a colossal conversion of potential energy into kinetic energy, which in such sizes, in the

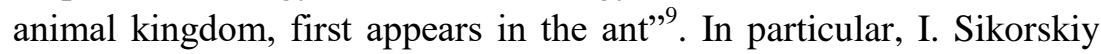
gives observations on the lifestyle and mental qualities of the ant of the English scientist John Lebbock (1834-1913), which showed that the ant has a short memory, which lasts no more than a few days, after which it forgets what it learned. Here, says Ivan Oleksiiovych, lies the reason for the extreme limitation of individual mental development of ant and other animals, which have short-term memory. Having a memory of the senses, the ant actually enjoys almost only one sense of smell, which plays a primary role for it: the ant determines the way, searches for food, searches for propupa with the sense of smell. Ants do not know each other personally, as personal familiarity is mainly based on visual impressions, and these impressions of ants are weak, and they distinguish the occupants of their nest from "strangers" by smell. Ant has a sense of anger for strangers and a sense of

${ }^{8}$ Sikorskiy I.A. (1909). Nachatki psihologii. [The beginnings of psychology]. Kiev: S.V. Kulzhenko. (in Ukrainian). P. 20

${ }^{9}$ Sikorskiy I.A. (1909). Nachatki psihologii. [The beginnings of psychology]. Kiev: S.V. Kulzhenko. (in Ukrainian). P. 21 
compassion for its own counterparts. But bees, which also have all senses, use not only smell, but also sense of sight, however, do not know each other personally and distinguish self from other with the help sense of smell too. In flights, movements, the bee enjoys sense of sight, visual representations and visual memory. It notices some bushes, flowers, trees and for them remembers the path to the hive and back. "But it also enjoys," writes I.O. Sikorskiy, "and the so-called "direction sense" that is, the memory of movements from the original point, and in case of assignment from the hive, bees, if they are released from different points away from the hive, each returns in a straight line to the hive. This ability to properly navigate is inherent in all animals in general, even those who are below" ". At the same time, the professor notes, that the limited mind of the bee, as well as the mind of the ant, turns out from the fact that the bee is not available the ability to personally meet their bees on the hive, there is only a total difference self from other, controlled by sense of smell. For example, if a bee is deprived of its sense of smell, fumigate with smoke, or sprayed with any other aromatic substance, the bee will lose its sense of smell for a few hours or days, and then it becomes possible to combine two swarms, without risk of collision between them, and in a few days they will already consider themselves "friends".

The significant mental development of fish is found out from the fact that fish can be trained, giving it lessons of impressions, for example, to call to feed under sound. In this case a sound from food and food communicate in one general chain of memory in mind of fish, and the first member of this chain as a signal, causes the subsequent number, that is idea of food, of the place of delivery of food and of the direction of the movement to food. "In training fish to swim for food by sound," writes the professor, "we meet with a new mental phenomenon - individual mental experience and development. This phenomenon in such sizes with such expressiveness is first found

10 Ibid Sikorskiy I.A. (1909). Nachatki psihologii. [The beginnings of psychology]. Kiev: S.V. Kulzhenko. (in Ukrainian). P. 22 
in the animal kingdom - in a class of fish" ". This phenomenon becomes possible, according to I. Sikorskyi, thanks to the existence of conception of a large brain in fish - a special organ of mental functions, which allows individual experience and development.

According to the views of I. Sikorskyi birds have all senses even in the embryon- everything that is intrinsic to man. In particular, their memory has characteristics of long-term (up to 3 years). And this fact the professor recognizes as a significant step in mental development, as with the help of this it is possible to accumulate personal experience and, thus, to expand and accelerate the course of individual development.

The professor argues that birds have developed aesthetic and moral feelings that provide birds with a huge boost to the mental process. "The aesthetic feeling of birds," writes Ivan Oleksiiovych, "is reflected in the fact that they love colors, admire them, appreciate each other; in addition, they also love singing"12. I. Sikorskiy is convinced that the development of aesthetic feeling is the most important biological event during the evolution of the animal world. Aesthetic feeling not only determines further progress, but also serves as a significant indicator of improvement of external organization. Aesthetic feeling indicates the existence of physiological energy surpluses, which is spent not only on external work, but also on improvement of spiritual organization.It is through the development of moral feeling of birds that they have a lasting family life.

Mammals already have the ability to remember their impressions and not forget them throughout their lives. The life expectancy of the elephant is quite significant among other mammals. Under favourable conditions, the elephant lives to the age of 70. The elephant has long-term and accurate memory; it recognizes a man as his leader even after decades. "Like bulls," the professor writes, "the

${ }^{11}$ Sikorskiy I.A. (1909). Nachatki psihologii. [The beginnings of psychology]. Kiev: S.V. Kulzhenko. (in Ukrainian). P. 23

12 Sikorskiy I.A. (1909). Nachatki psihologii. [The beginnings of psychology]. Kiev: S.V. Kulzhenko. (in Ukrainian). P. 23 
elephant has higher feelings. An elephant can revenge if it gets annoyed by injustice. But he also can be generous, that first appears in the world of animals. For the first time we meet true love at the elephant: the elephant goes to captivity for captive children, which do not do other animals, even monkeys, who put the personal benefit above altruism"13. Observation data of elephants prove that they have developed patience and meekness, and the elephant approaches the dog by its gentle feelings, and by mind - to monkeys.

I. Sikorskyi reports that the $\operatorname{dog}$ occupies almost the first place in the classification of animals in relation to the development of higher feelings. Its loyalty to the master is set by people as an example. The dog has a sense of guilt, but has no sense of shame. If the sense of guilt is a precursor to shame,the dog is superior to almost all animals in this respect. Dog is the only animal a man has brought closer to himself as a friend.

Having a brain equal to the third part of the human brain, or equal to the weight of the brain of a newborn child, the monkey remains, from the point of view of man, according to the professor, a child, a jerk, despite lightning-fast mental manifestations sometimes. The monkey is characterized by special interest and copying. The feelings of monkeys, especially the feeling of sympathy, are developed very subtly and is manifested in the care and love for their children. Depth of feeling of the suffering monkey is quite significant. I. Sikorskyi calls the mind the strongest aspect of the monkeys` psyche, and the will considers weak, as the monkey cannot control itself; the behavior of monkeys is very active, fun, mobile and does not have the self-control necessary for mental development.

The first thing the professor points out in describing the features of human psyche development is the size of the brain: it is the largest compared to all animals and is very different from them by its mental qualities. And although this difference between human and animal psyche is obvious, according to I. Sikorskyi it was not scientifically

${ }^{13}$ Sikorskiy I.A. (1909). Nachatki psihologii. [The beginnings of psychology]. Kiev: S.V. Kulzhenko. (in Ukrainian). P. 24 
formulated at the time, and therefore animal psyche was too overestimated, then put at too low level. The essence of this difference is shown by the professor by example: "Spider builds its spider net subtly and very properly, and it seems that with this experience it is easy to go on in the system of constructions. Or nightingale: it sings so artistically that man admires its singing. The dog shows superior qualities, such as loyalty unto death, responsibility, affection, seemingly this is enough for further significant improvement. Meanwhile, reality shows a completely different thing: the spider can do nothing but its traditional net, the nightingale can sing nothing more, except the only aria, finally, the dog, showing high feelings, at the same time is deprived of a sense of shame, and does not even have germs of this feeling, and the man calls cynicism (by the nameof the $\mathrm{dog}$ ) the manifestation of severe forms of effrontery in the human race not without reason"14. But the person has no such mental narrowness, convinced I. Sikorskyi, "having studied one song, he can study and sing a dozen and hundreds of other songs; able to inweave one net, he can inweave many other nets; having one feeling is not not lacking in others" ". The professor sees the essence of this wide difference between the two psychologies - human psychology and animal psychology in that animals have not psyche, but separate elements of it. "The soul of animals is an artistic music box," the professor writes, "which can only play one aria if it is turned over - to give a boost from the outside. The soul of man is organized on similarity of a musical box with an infinity of keys, while with a wide opportunity to vary keys and receive innumerable quantity of plays, elegant works, unseen subtle combinations through various rearrangements" ${ }^{\prime \prime}$. In cases of juvenilism of mental abilities of a person, for example, of an idiot, his mental model resembles features of an animal psyche, for example,

${ }^{14}$ Sikorskiy I.A. (1909). Nachatki psihologii. [The beginnings of psychology]. Kiev: S.V. Kulzhenko. (in Ukrainian). P. 25

${ }^{15}$ Sikorskiy I.A. (1909). Nachatki psihologii. [The beginnings of psychology]. Kiev: S.V. Kulzhenko. (in Ukrainian). P. 25

${ }^{16}$ Sikorskiy I.A. (1909). Nachatki psihologii. [The beginnings of psychology]. Kiev: S.V. Kulzhenko. (in Ukrainian). P. 25 
there are so-called idiots-geniuses who are able to draw a bird or only the head of a bird artistically, but further this cannot take a step. The psyche of animals is strong only within instinct (food, sleep, selfprotection), where the excitatory tendency of sensitive and mobile mechanisms is almost as large as that of humans, and where perception of impressions and their recognition takes place quickly, clearly, and as quickly and accurately followed by a movable reaction; but beyond instincts, the nervous system remains almost undeveloped. According to I. Sikorskyi all segments of the nervous system of a man, included in the chain of instincts, like those that do not included, are developed equally enough and completely. Long-term memory (for life), subtle movable associative mechanism, all kinds of feelings is the principle of human psyche. "If you take away a person "s shame," writes a representative of the Kyiv School of Philosophy of psychology - or any other feeling - he will turn into a moral idiot into an animal. And only the completeness and development of all sides and all units of the psyche ensure his humanity " $" 17$.

\section{Development and change in human mental development by age}

The greatest masterminds of the past - Aristotle and Plato, Spinoza and Kant - were once children and their comprehensive world psyche developed slowly, gradually taking the usual path of helpless infant thinking. This path is rich in supreme interest and is able to excite deep feelings in the observer-psychologist.

The psyche of the newborn develops constantly, turns into the psyche of the child; psyche of a child turns into psyche of a young man by means of colossal tension of forces, then becomes psyche of an adult person, and in old age - psyche of a person in age.

Scientists divide the whole cycle of mental evolution of man in philosophical psychology of the late XIX - early XX century as follows:

${ }^{17}$ Sikorskiy I.A. (1909). Nachatki psihologii. [The beginnings of psychology]. Kiev: S.V. Kulzhenko. (in Ukrainian). P. 26 
I. Psyche at the age of the first childhood (from birth to 7 years).

II. Psyche at the age of second childhood (from 7 to 14 years).

III. Psyche of young age (from 14 to 22 years).

IV. Psyche of mature age of a person (from 26 to 30 years).

$\mathrm{V}$. The psyche of the ageing period (45-55).

Psyche and its development in the first age of childhood. The age of first childhood is divided into the following periods where each has the main characteristics and way of transition to the following higher degree of mental life:

1. Newborn psyche, or infant psyche.

2. First three months after birth.

3. From the fourth to the tenth months of life.

4. The end of the first and the beginning of the second year of life.

5. From the second to the sixth year of life.

It is proposed to start consideration of the newborn psyche in parallel with two series of phenomena: external organization and mental competences. First of all, the attention of the psychologist should be focused on the face of the child and on all his appearance. If no defects and handicaps are noticed in external development, all this, according to the representatives of the School of Philosophy of psychology of the late XIX - early XX century, presages the normal course of mental development of the child. At the same time, children with some physical disabilities are not always deprived of the possibility of normal mental development.

In the first days after birth, only nerve centers, which are responsible for reflex actions, are developed in the child. However, the infant, as the adult, has phenomena of a purely physiological nature in which no mental content is noticed, but there are also phenomena that bear absolutely mental reflection. Also the presence of intermediate type phenomena, which can be classified as either physiological or mental, is recognized in philosophical psychology, but during this period this issue has not been solved.

Physiological phenomena include the response of external organs to irritation (e.g. tickling or tingling). The child closes his 
eyelids, sneezes or coughs if he gets anything into the airways. Newborns also have much more complex types of movements and phenomena, where the activities of those complex mechanisms that regulate themselves and act automatically are observed. These include the regulatory mechanisms of the heart, the mechanisms that regulate body temperature and make the breathing process possible.

In the first days from birth, the child already has the ability to taste and olfactic perception - the ability to taste and olfactory cognition; the infant pays attention to these perceptions, that is, focuses on them and holds them by connecting bulesis. The infant has the ability to remember taste and olfactory impressions and distinguish them. But at this time, the child has no idea of sound or light. Regarding feelings, a newborn child is deprived of any specific feelings. His psyche is only accessible by states of pleasure and displeasure and a sense of pleasant and unpleasant in his simplest undeveloped features. Such a feeling or mental state is also characteristic of the psyche of an adult, where it is used along with other absolutely clear, complete and certain states of psyche and mood. For a newborn child, the presence of two opposite common conditions - pleasant and unpleasant - make up the only possible form of feeling.

In the first three months of his life, the child learns to hear, see and touch. There is an active process of learning of the child's own senses. The direct organ for the perception of his body is a myriad of sensual centers scattered across the skin, mucous membranes, muscles and internal organs. Because of nerves there are billions of impressions every second and they continue their way to the cerebral cortex, that is, the sphere of body sensations or the tactile sphere. The development of visual perception and attention can provide a clear explanation of the work of complex processes of a biologically and psychological nature that occur in the child 's body during the first three months after birth. Finding out this question is absolutely important not only for the psychology of childhood, but also for general psychology. The core of the issue is that the child does not know how to control eye muscles in the first days after birth and an 
important part of the visual apparatus occupies a completely random position in relation to visual objects every minute. The child must make constant efforts, continuous stresses to adapt his visual apparatus and learn to use his vision tool.

The representative of the Kyiv School of Philosophy of psychology I. O. Sikorskyi believes that for the foundations of mental development of the child hearing is more important than vision. And this can be seen, according to I. O. Sikorskyi, by watching blind and deaf children. "A deaf child," writes the professor, "develops spiritually to a much lesser extent than a blind child, and this can be noticed very early, already in the first months of life" 18 . At the same time, development of hearing in the first days after birth does not occur in all children at the same rate. But it can be considered that on the second or third week of life almost all children begin to hear. In confirmation of that, it is possible to view sudden closing of the eyelids with any strong sound. With further development the child flashes the handles in response to a strong or sudden sound. If the sound is strong and lasting, the child gets worked up that is expressed by fidgets and then begins to cry. By the end of the second, and more often before the beginning or even the end of the third month, the child turns on the sound and holds his ear towards the sound. The child also begins to listen to sounds from movements of his own body, breathing and even beating his heart.

By the end of the first month from birth, the first specific feelings become visible - feelings of suddenness. Although this feeling does not differ by clear content and certain well-being even of an adult person, however, due to his unusual objective clarity of the child I.O. Sikorskyi gives him the importance of an independent nervous-mental state, which should distinguish from other feelings that develop later - surprise and fear.

The sense of suddenness lies in the external stop of mental and some nervous processes, which for a short time - up to half a minute -

18 Sikorskiy I.A. (2009). Duha rebenka. [Baby Soul]. Moscow: Astrel. (in Russian). P. 59 
suddenly last, as if all nervous acts had received a reverse or a boost. In its simplest forms, a sense of suddenness appears to be a purely physiological process; in its higher forms it is also filled with physical elements. The delay of nerve acts in a state of suddenness can sometimes precede eye flashing, handle lifting, and general tremor. The feeling of suddenness for the child is caused by strong sound impressions already in the first week after birth, as well as under the influence of other irritations received from any organ of feelings. A sense of suddenness borders between pleasant and unpleasant feelings and can move into other mental states, increasing their strength and tension.

The period from the fourth to the tenth month of life plays an important role in the mental development, because exactly at this age begins the highest mental activity. New at the beginning of the fourth month is the fact of recognition of visual and auditory impressions. Recognition of the child is a active joy, energy and a long concentration. Mental life becomes conscious, takes a new direction due to the emergence of consciousness and will, has other goals, takes new external forms, and recognition becomes an effective act and indicates the emergence of associations of the child, that is, the ability to associate some mental acts with others and thus establish the continuity of their sequence and course.

Thus, the beginning of the fourth month of a child 's life is characterized by the following significant signs:

1) is formed the ability to concentrate visual perception;

2) ability to recognize previous impressions (visual and auditory)

3) expression of emotion of joy in causal connection in act of recognition;

4) the desire to find new impressions and the combination and bonding of the obtained impressions into thought rows and chains;

5) ability to generalize, to form thought formulas, to transform unconscious associations in the process of thinking;

6) the main feature of this period constitutes the development of associations. 
The next period of mental development covers the end of the first year and the beginning of the second year. During this period of life of the child there is development of one of the highest mental functions - speech development. When the thoughts of the child, mental acts, memory are already at a certain level of development the word begins to become a need. Speech development begins after the child has achieved some success in mental development and when his will is somewhat stronger.

Usually a child starts talking before walking. And therefore, this fact alone points to the importance of speech in a number of processes of mental development, especially since speech movements belong to the category of the most complex movements in the human body. The essence of speech and its complexity lies in complex nervous-mental work, which is hidden under the sounds of words. There is no speech in the presence of severe cognitive impairments. Speech development from philosopho-psychological positions is divided into three periods: 1) study of sounds (4-6 months), 2) understanding of words (10-12 months) and 3) pronunciation of words (after 12 months).

The period from the second to the sixth year of life is characterized by the even development of all aspects of mental life with the development of speech inclusive. From an anatomical point of view, this period is similar to previous periods, but differs from the following period (second childhood) in that anatomical development of the brain continues during it. The essential sign of this period is the integration of all processes of feeling, thought and will into a whole unified human personality. During this period it is already possible to talk about the temperament of the new personality, which is determined, as well as about possible abilities. Feelings during this period are nonsustained and weak. These feelings may seem strong, but they are actually weak and shallow, at least early in this age period. Their perceived strength depends on the fact that they are not subject to the deterrent influence of will, at this time is very weak like thought. Representatives of philosophical psychology notice two trends in all further development of the child - constant development of feelings and constant suppression of them by growing will. It is 
about oppression, not destruction, because in reality feelings that are constrained by will do not disappear, but turn - then into complex and high feelings, then into deeper ones. The weakness of the child ' $\mathrm{s}$ feelings is expressed in the fact that children quickly forget the experience and move from one mood to another. The feeling that is characteristic only of man - shame - develops not earlier than the third year of infants' lives; the accusativeness lies in the relationship to the sense of shame and precedes it in development time. The accusativeness manifests itself very early and in a mature and serious form. The development of such higher feelings of the child as aesthetic, intellectual and moral also takes place in this age period. Close to moral feeling in philosophical psychology of the late XIX early XX century is considered a religious feeling. This feeling refers to the most natural feeling of the child and to neglect the development of this feeling is equivalent to not recognizing the natural laws of human mental development.

The development of feelings precedes the development of thinking processes and will, and by the end of the period this difference is kind of increasing. Under such conditions, children particularly need support and care. The development of feelings between the ages of 3 and 5 gives children special psychological features: they are gentle, sensitive, bruise, but at the same time sensual and weeping, exposed to short-term and even often deep subjectivity. All this is signs of feeling that is rapidly developing. With the end of this period, the development of feeling is already much slower. This period may delay (moving to 4-6 years), then comes much earlier, for example, earlier than 2 years of life. Children's feelings in accidents develop especially rapidly.

Regarding mental abilities in the period under consideration, philosophers-psychologists point to their weakness and fragmentarity of thinking. Children's perceptions, concepts and thoughts are fragmented and filled with gaps that depend on lack of experience; these are only individual episodes, far from becoming "the whole". At this age, it is still difficult for children to absorb and notice things which many times were before them. For this purpose it is necessary to 
train arbitrary attention, and it is not as simple task as seems and not only for children, but also for adults. The importance for the mental development of the child does not cease to play also external impressions of the organs of vision and hearing.

The level and course of mental development in the period from 2 to 6 years from birth are indicated by the peculiarities of the manifestation of will processes. The will of children is rather weak in this period. It is expressed first of all in inability of the child to hold back tears, laughter, mischief, anger, shyness, rage and even (at the age of 2-3 years) to control a bladder. The latter may even serve as a measure of child's will development: early developed tidiness in the toilet is a good sign; on the contrary, the inability to enforce it indicates a weakness of will. The weakness of the child 's will is also evident in the humble and unconditional obedience of the child to the strongly expressed will of the adult. The development of will is perceived: 1) in the agility of hand movement, 2) in the expressiveness of language, 3) in proper walking, and 4) in developed attention. Will acts as a certain "anchor," the last experience of thought and therefore develops somewhat later than intelligence.

The development of the child 's personality takes place through personal efforts and intensenesses and the emergence of selfcomprehension. But for a long time the child does not realize himself, has no idea about himself and does not remember himself. Gradually, however, step by step, the child begins to distinguish and separate the entire outside world from himself. It is from the moment of the onset of self-comprehension, according to the views of representatives of philosophy of psychology is formed a personality and now "selfimage" of the child becomes the core of consciousness, has its present and past and lives a happy present, before which the future is unnoticeably prepared.

In the second half of the period under review of the child 's life (4-6 years) happens growing and personality development, and the child is gradually knowing himself and the outside world. The most important auxiliary tool in this knowledge, both of himself and of the outside world, now becomes the word. The exchange of opinions with 
others and the translation of his thoughts and feelings into words gradually deepens knowledge, and makes the inner world of the child, which is revealed, more and more clear and tangible to him. This inner world is subjective, which cannot be seen by an outsider, thanks to words becomes heard, understandable, tangible and objective. Philosophers-psychologists are convinced that communication with adults, life with them is the main source of mental development of children at this stage of life, when the use of methods of scientific development of higher mental manifestations is not available yet.

Developmental abnormalities of mental manifestations are considered to be: a) the imbalanced development of feeling, mind and will, $b$ ) the prevalence of perceptions over thinking, and c) the child 's pamperedness and a total absence of authority. Signs of mental development are normally considered to be: a) fun and vitality of the child, calm and sufficient sleep and appetite, rare and short tears, b) capture of the child by the game, c) daily notable cerebral successes (new words in the language, new items for the game and new objects of attention), d) activity, mobility of the child emerging from intellectual requirements, and e) independence of the child, which early manifests itself in games and pursuit.

The next period of mental development of philosophy of psychology is psyche at the age of the second childhood (from 7 to 14 years). Entering the period of the adolescence, the child has all basic mental abilities: feelings, attention, ability to arbitrary attention, will features, memory, certain mental abilities. But the development of mental competences of everyone has its own peculiarities and a certain unevenness in their development. From a psychological point of view, a child of this age can be equated with an adult in qualitative terms, but in quantitative terms there is still a significant difference.

In the age period of 7-14 years, the developed side of mental life is feelings; will processes and mental processes are somewhat inferior. Mental development concerns mainly the last two manifestations of mental development. And although children of this period already have an excellent memory, it turns out to be excellent only for casual perceptions and associations. As for arbitrary attention, it is 
considerably weaker. The teenager should engage in long-term exercises for getting necessary level of arbitrary memory (i.e. associations and reproductions). Therefore, systematic mental work is difficult to some extent, but for simpler tasks, both memory and automatic attention are sufficiently developed.

The main features of personality character between 7 and 14 years are so pronounced that in some cases it is possible to determine character. Mental states at this age are not such that autonomy and independence of actions are impossible, children of this age willing or not obey others. In most cases, at the end of this period, mental conditions change very significantly, and in these cases, according to the opinion of representatives of philosophy of psychology, the existence of a transition or intermediate period should be allowed.

This transition period (12-15 years) corresponds to the last years of the adolescence and stands on the border line of youth. At this age, there are physical and moral changes that predate youth. Physical changes consist in accelerated body growth and the emergence of the first visible sexual signs, the display of courage and femininity. The psychological characteristics of transition age are as follows.

During the development of feelings, become visible fluctuations or stagnation caused by the peculiarities of psychophysiological development. Mental capacities continue to develop constantly, however, due to fluctuations, the sense of mental work is less successful. Mental abilities at the beginning of this period are characterized by a weak ability to compare and generalize, to assess and criticize; they are more prone to individual work and to specific, small mental exercises. The will, as opposed to other manifestations of psyche, begins to grow strongly, continuously successfully increase. However, this build-up does not yet create a character, as character is due to the general development of feeling and will. At this age it is found meaningless child heroism, in a tendency to fabulous feats, where large and funny, mature and child are inextricably connected to each other. 
The next period in human mental development according to philosopho-psychological tradition is youth. Youth begins at the age of about 15, at the age of 18-20 years moves to mature youth and then, to mature age.

The development of the psyche during youth coincides with quite significant processes of physical development, so that both cycles of phenomena are in some ratio and connection, at least in time. The period of youth from a philosopho-psychological point of view is characterized by the excitatory tendency of all mental manifestations feelings, mind and will. This excitatory tendency is a deep organic process that is never repeated in life again. This is the important psychological and educational effect of youth age.

With the onset of youth, feelings become extremely deep, sincere, and perfectly pure. In youth, the will is rapidly strengthened and provides the mental structure with the character of determination, courage and independence. But the greatest changes are taking place in the thinking process. The main feature of mental development in youth is seen in the deep desire to highlight and unite all mental manifestations, to combine into one all impressions, which are stored in memory and to have a single whole world view, having reconciled all contradictions and solutions of all problems for himself. During this period, the question of mission is decided, and a plan for all subsequent life is drawn up. The changes that occur in mental development at this time bear the typical seal of the ideological process, so to speak, with broad plans and a brave flight of thought.

The correct course of mental development of youth manifests itself in restraint. Representatives of the Kyiv School of Philosophy of psychology I. Sikorskyi and Zenkovskyi note that life does not require young people to do business, providing an opportunity to develop, think about their mission, expand their outlook, create programs of life. Youth is mainly devoted to this: it is all in the future and lives hopes. The older generation acts until it is helped and replaced by mature youth "Like love," writes Ivan Oleksiiovych, "which has the power to change man, and all the processes taking place in the young soul leave an indelible mark in it, which becomes a living and vital 
beginning throughout person's later life. From that youth is dear to us as a period of great transformation of the soul, when everything exalted, strong and good fills it" $"$.

In order for this organic process to occur correctly during the youth period, according to philosophers-psychologists, continuous efforts are needed from a growing person to meet the needs of the psyche that are revealed. The actions taken to develop the psyche during this age period have a decisive impact on the following age periods of a person 's life.

The next period of human mental development is mature age. In the physical sense, this age begins with the end of growth of the body, at the age of about 26-30 years, but mental maturity, said representatives of philosophy of psychology, comes earlier at this age. Often, however, mental maturity is lagging behind, which is reflected in the lack of development of the will sphere of the person and from this lack of self-control, despite a sufficient level of development of mind and feeling.

Mature age is a period of human activity and is characterized by a desire to achieve life goals and objectives. "Activity and the implementation of tasks," the professor writes, "is a direct natural duty of a person at a mature age; at the same time, it is also a moral duty, according to the great principle that every tree which does not bear good fruit will be cut down and thrown into the fire" 20 . The formation of man as a person takes place directly in activity. Person's identity and his individual characteristics influence the very nature of activity and the way of carrying out life duty in mature age. So, the properly spent youth brings to mature age not only programs and plans, but also that reserve of energy and internal tension, insists Ivan Oleksiiovych, "which is the true grain of the future big tree" 21.

\footnotetext{
${ }^{19}$ Ibid. Sikorskiy I.A. (2009). Duha rebenka. [Baby Soul]. Moscow: Astrel. (in Russian). P. 145

${ }^{20}$ Ibid. Sikorskiy I.A. (2009). Duha rebenka. [Baby Soul]. Moscow: Astrel. (in Russian). P. 146

${ }^{21}$ Ibid. Sikorskiy I.A. (2009). Duha rebenka. [Baby Soul]. Moscow: Astrel. (in Russian). P. 147
} 
Mature age is the age of practical life, as opposed to the ideological life of youth. With the correct mental development, youth and maturity are as different from each other as the project and its execution are, or as the idea and its concrete implementation. However, the realization of specific tasks and individual goals of life is able to introduce, and sometimes introduces into a mental device some unilateralism, which is fixed by time and habit. Hence there is a kind of psyche specialization in a known direction with violation of its ideal completeness. Under such conditions, mental life could become unilateral and narrow down to a certain extent if not for the existence of moral adjustments. Such adjustments in philosophy of psychology recognize religion, science, family, social life and psychological difference of sex, because they contribute to the psyche the diversity, breadth and depth that supports mental completeness and integrity of man. Special immediate activity value is attached to the family with its interests, where the role of woman in the family is recognized as the leader. A woman 's psyche is recognized as much more flexible than a man 's. Thanks to the greater development of feelings, a woman always keeps more idealism and breadth in her psyche for old age, with signs of innocent childhood of perfect youth than a man. That is why a woman is largerimbued with the understanding of a young man who grows up, than a man, and is a natural link of two generations who are united in a family.

The main errors of mental development, according to the representatives of philosophy of psychology, which are most inherent for mature age, are the underdeveloped, weak will of men and the lack of tactile and subtle development of feelings of women. Under the above-mentioned conditions, a man becomes little active and unstable, and a woman is in danger of moral submission to the environment and routine, with a loss of ability to experience higher feelings and moral brilliance.

Periodization of human mental development in philosophy of psychology of the late XIX - early XX century concludes with an ageing period. In this period, between 45-55 years of age, begins a decline in the physical life of the body, reflected in a decrease in the 
size and dimensions of all organs of the body, including the brain. Such a change cannot but affect mental manifestations, at least in quantitative terms. In this sense, the psyche of a person of this period differs from the psyche of other age periods of life. "However, it is not necessary to think," writes Ivan Oleksiiovych, "that in the soul of the elder there are phenomena of mental decline and destruction of those outstanding beginnings, which we call the human heart, the human spirit. It happens to be that! But we will not stop on pathology or deviation; our task is to describe the natural course of mental evolution with age. Not only painful old age, but also improperly performed, inactive youth is full of mental gaps and shortcomings, but they are exceptional phenomena" 22 .

At the same time, despite some physical weakness of the nervous system and brain for the age period, the considered mental activity can be quite productive at tireless work and tension and activity of thinking processes, contributing to development and improvement of efficiency. I.O. Sikorskyi gives an example of direct correlation. "A study of the brain of Helmholts, Mentsel, etc., found that constant mental and moral tension protects brain tissue from destruction and maintains it in a state of physiological vitality. Everything in the body of such a hard-working person ages, all organs - heart, muscles, bones - atrophy, but the organ of thought brain - remains preserved, the hand of time does not touch it. It is a consolation for those approaching the deadline for human life. Let the body be destroyed - such are the laws of nature, but let man not leave clarity of mind, willpower and flame of the heart until the last minute of life" 23 . There are many examples of the life of great people in history, where such an achievement is presented, and the way to this is the continuous improvement of mental manifestations. Genius, I. Sikorskyi argues, means continuous work, where the latter with

22 Sikorskiy I.A. (2009). Duha rebenka. [Baby Soul]. Moscow: Astrel. (in Russian). P. 148

23 Sikorskiy I.A. (2009). Duha rebenka. [Baby Soul]. Moscow: Astrel. (in Russian). P. 149 
development and improvement of mental is not so much a gift of nature as a credit of personality.

The development of human psyche during old age reaches the highest degree. No age period compares with old age according to life experience and the moral development that man reaches at the end of his life. The further continues life in old age, the fewer remain those who were close and important, with whom the person became related and got closer. Understanding his extremity, which approaches every day, man increasingly seeks to live, to be necessary not only close to his family and friends. Old age should be full of unconditional love for people, because this attitude towards people, including the world around him, indicates that man in previous periods of life paid attention to his own development, improved his mental competences and higher feelings. And in general, as the representatives of the School of Philosophy of psychology of the late XIX - early XX century are certain, man of this period is an embodiment of wisdom and a model of pure and sublime concept of duty.

\section{CONCLUSIONS}

Mental development issues at the end of the XIX - beg. of the $\mathrm{XX}$ century in psychology occupies the main place in scientific search of representatives of the school of philosophy of psychology. Appear publications, books in which ideas of problems of human psyche development are presented. The works cover the facts of observations of children, their development of sensations, emotions, movements, will acts, speech, thinking and self-consciousness.

In the late XIX and early XX centuries were published many diaries of educated parents, in which they recorded the results of their observations of the mental development of their children in early and pre-school age.

From the late XIX century and in the early XX century, societies of child psychology began to be organized in different countries, and books from its general and special issues began to be published more often. In Germany, books were published by W. Shtern (1871-1938) on the mental development of children before 
the age of seven, on the development of speech, a mention in early childhood, and K. Hross (1916-1946) about children and animals. In France, A. Bine (1857-1911) initiated the study of mental development. At his school, were published a number of works about the peculiarities of the development of attention, memory, imagination, thinking, curiosity, aesthetic feelings and will of children, about their visual activities. He created the first tests of mental intelligence.

In England, were published books about methods of studying different aspects of mental development, about the characteristic features of childhood in its early stages (D. Selly). Psychological research not only of childhood, but also of youthful age developed in the United States (S. Holl). There was born the idea of creating a holistic science about the child (pedologia), which found its fans around the world for a while. However, attempts to implement this idea have proved ineffective due to the error of theoretical foundations and the lack of reliable data on various aspects of the child 's mental development. The latter was understood by the proponents of this idea as a biologically conditioned process. In contrast to the biological direction in the domestic school of philosophy of psychology of the late XIX and early XX centuries, the understanding of mental development was based on ideas about mental as a special substance.

\section{SUMMARY}

The presented results of the theoretical study reveal the peculiarities of understanding the idea of mental development of man in the philosopho-psychological tradition of the late XIX - beg. of the XX century. The material reveals characteristic features of mental development in different periods of human life. The mental development of a person was divided into the following periods: I) psyche at the age of the first childhood (from birth to 7 years): a) psyche of a newborn, or psyche of an infant, b) the first three months after birth; c) from the fourth to the tenth month of life, d) the end of the first and the beginning of the second year of life, and e) from the second to the sixth year of life, II) psyche at the age of the 
second childhood (from 7 to 14 years old), III) youth psyche (1422 years old), where there is a separate transition period (12-15), IV) the psyche of mature age of a person (26-30 years) and V) the psyche of the period of ageing (45-55 years).

\section{REFERENCES}

1. Zenkovskiy V.V. (1914). Problemu psihicheskoy pricheskoy prichinnosti. [Mental causation problems]. Kiev: Imperatorskiy Universitet Sv. Vladimira. (in Ukrainian).

2. RomenetsV.A. (2005). Istoriy psihologii. [History of psychology]. T. I. Kiev: Publishing "Libid". (in Ukrainian).

3. Sikorskiy I.A. (1909). Nachatki psihologii. [The beginnings of psychology]. Kiev: Publishing S.V. Kulzhenko. (in Ukrainian).

4. Sikorskiy I.A. (2009). Duha rebenka. [Baby Soul]. Moscow: Publishing “Astrel”. ( in Russian).

5. Chelpanov G.I. (1915). Ychebnik po psihologii (dly gimnaziy I ychilich). [Textbook of Psychology (for gymnasiums and self-education)]. Moscow: Publishing V.V. Dumnov. ( in Russian).

\section{Information about the author:}

Oksana Melnyk,

Candidate of Psychological Sciences,

Senior Research Associate,

Doctoral Student at the Department

of Developmental Psychology of the Faculty of Psychology,

Taras Shevchenko National University of Kyiv ORCID ID: orcid.org/0000-0002-8652-6833 